تأثير مكمل سازى بذر كتان و تمرينات تركيبى بر ظرفيت آنتىاكسيدانى تام پلاسما و شاخص ير اكسيداسيون لييدى زنان داراى اضافه وزن

*اطمه حلالخور

ا- كارشناسى ارشد تغذيه ورزشى، گروه فيزيولوزى ورزشى، دانشكده تربيتبدنى و علوم ورزشى، دانشكاه

تبريز، تبريز، ايران

*آدرس مكاتبه: آذربايجان شرقى، تبريز، بلوار و ب بهمن، دانشكاه تبريز، دانشكده تربيت بدنى و علوم ورزشى،

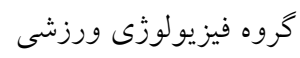

تلفن: ع.4.

fateme.halalkhor@gmail.com : بست الكترونيك:

doi: $10.29252 / j m p .2 .70 .144$ qV/4/4

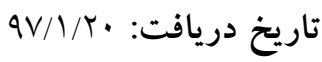

جكيuه

مقدمه: جاقى با افزايش استرس اكسايشى بدن همراه است. به علاوه، فعاليت ورزشى باعث افزايش استرس اكسايشى مىشود. با اين

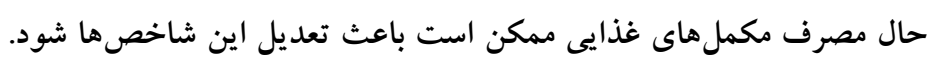

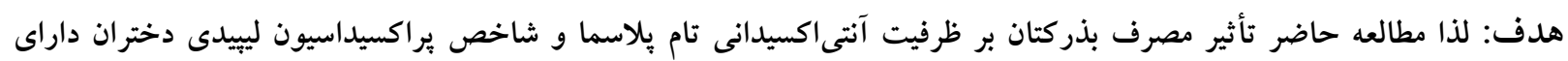

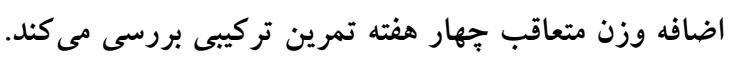

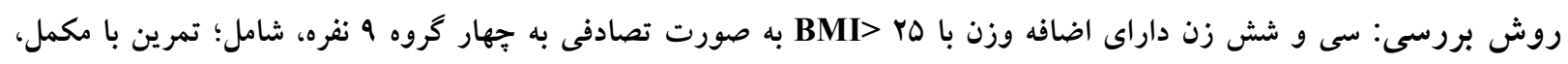

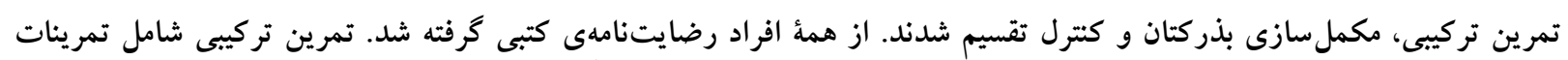

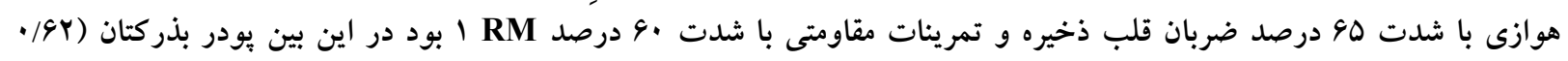

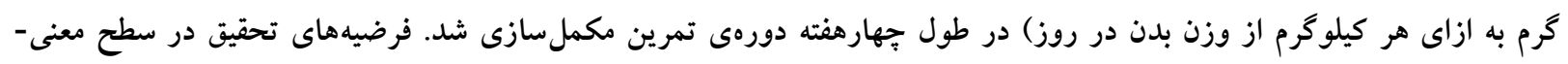

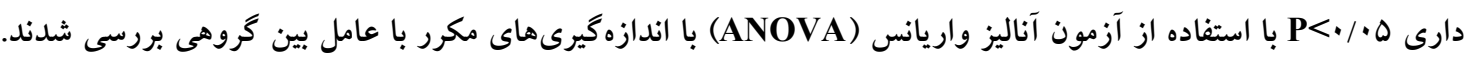

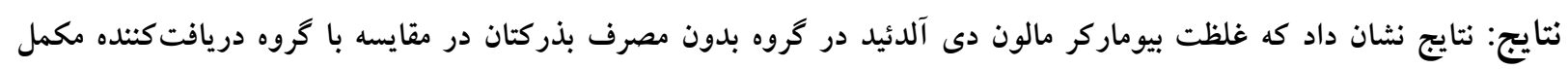

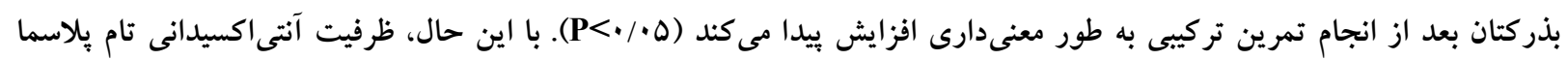

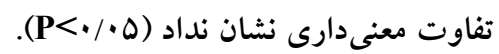

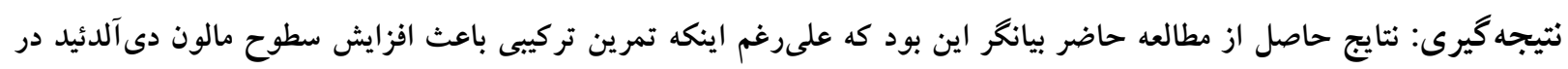

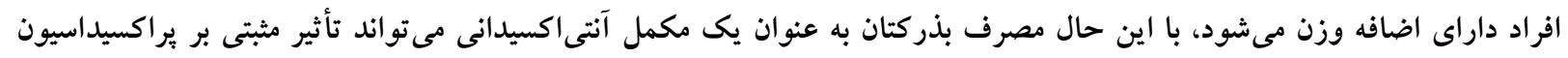

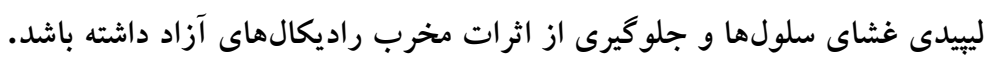

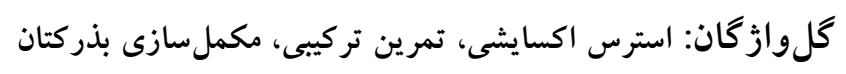


تأثير مكمل سازى بذر كتان ...

غشاى ليبيدى سلول)، به عنوان مكانيسم احتمالى درخير در

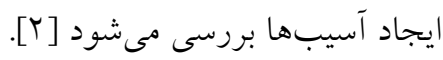

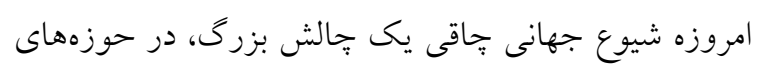

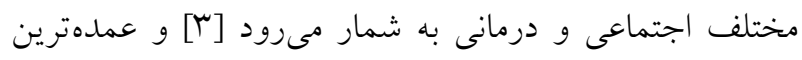

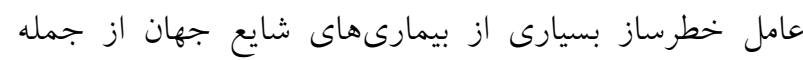
ديابت، بيمارىهاى قلبى - عروقى، فشارخون بالا، اختلالات

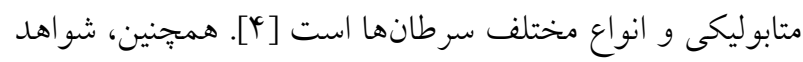

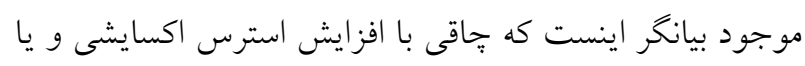

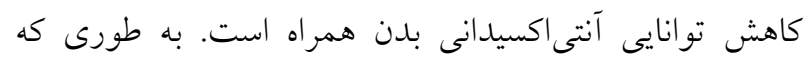

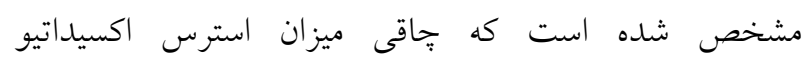

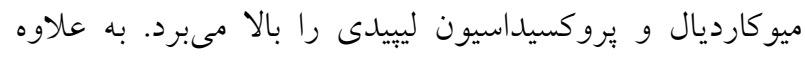

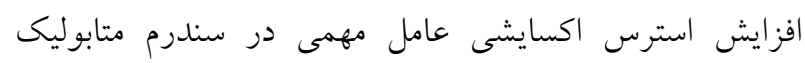

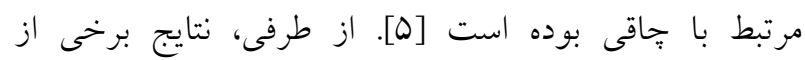

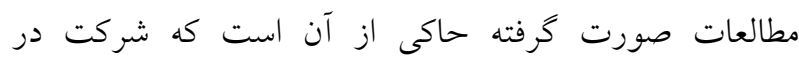

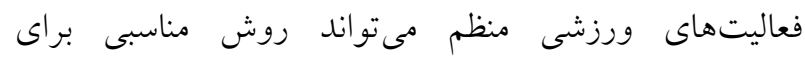

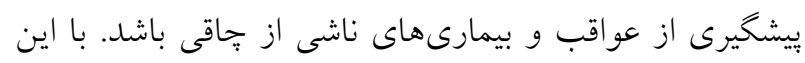

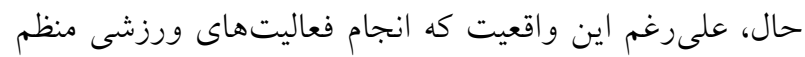

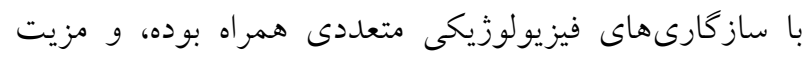

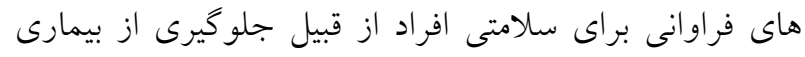

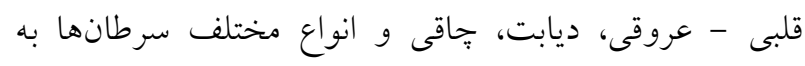

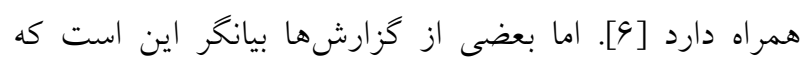

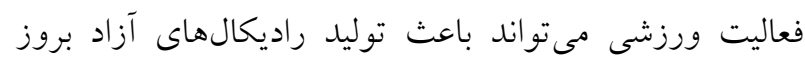

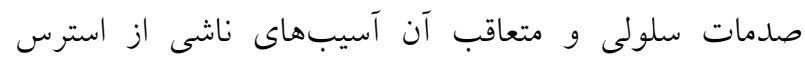

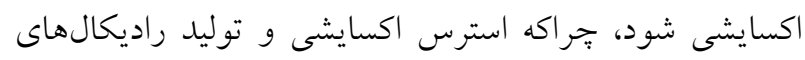

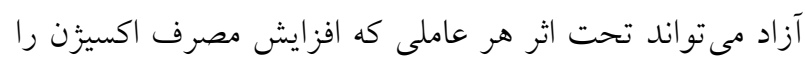

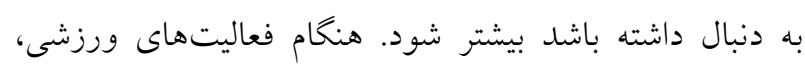

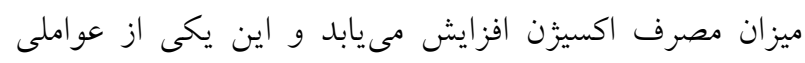

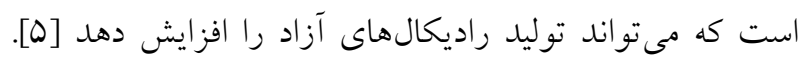

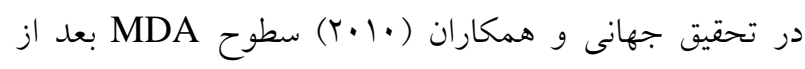
هشت هفته تمرين ورزشى منظم و مستمر افزايش معنى دار دار

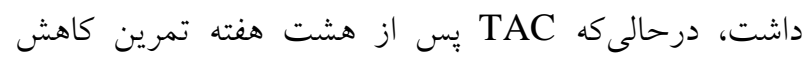

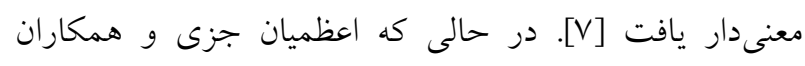

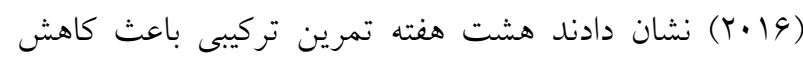

\section{مقلم مه}

راديكال آزاد اتم يا مولكولى است كه با داشتن يك يا جند الكترون

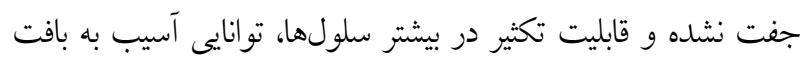

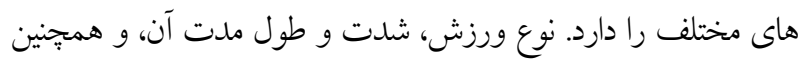

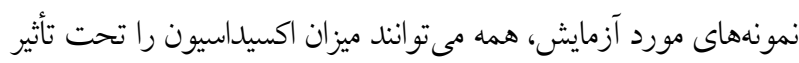

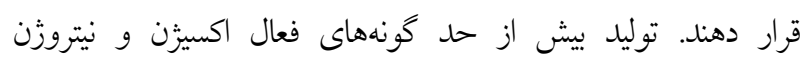
(RONS (Reactive oxygen and nitrogen species)) مى تواند از قرار كرفتن در معرض انواع محركها، از جمله، استرسهاى

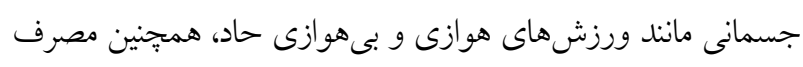

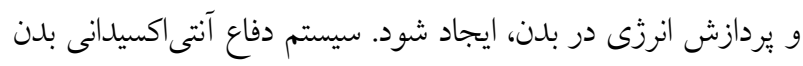

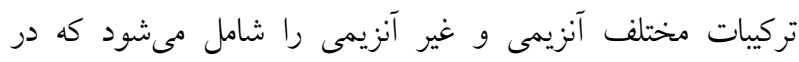

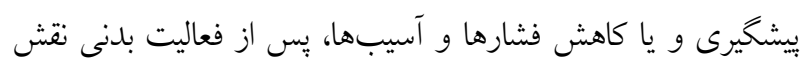

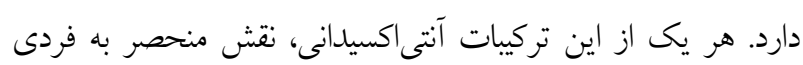

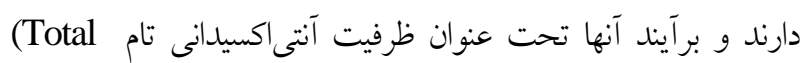

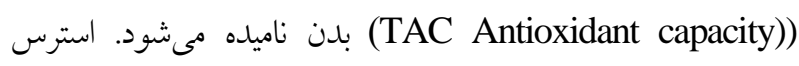
اكسيداتيو زمانى اتفاق مىافتد كه عدم تعادل بين سيستم آنتىاكسيدانى

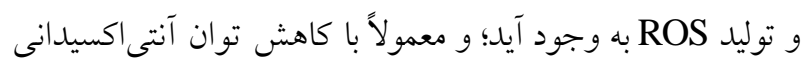

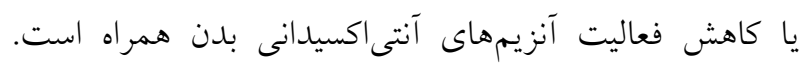

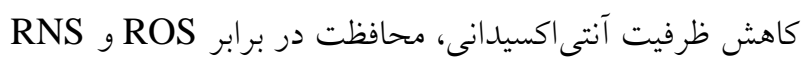

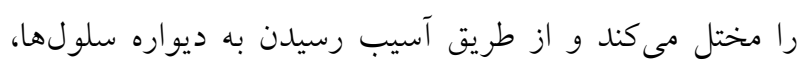

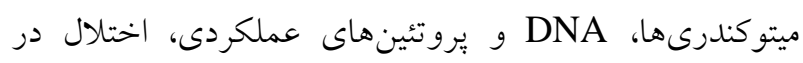

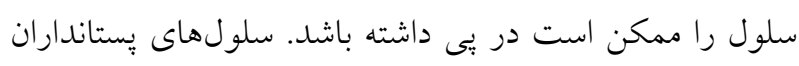
به هر دو سيستم آنزيمى (آنزيمهاى سوير اكسيد دسموتاز،

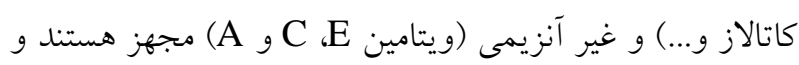
بدين طريق، ROS را حذف مي كنند. آسيب با كاهش فعالئ واليت

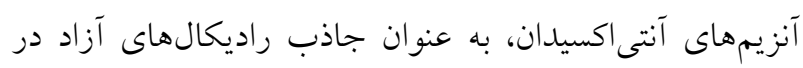

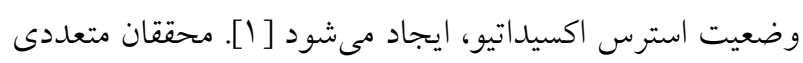

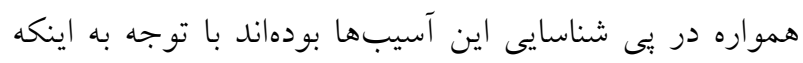

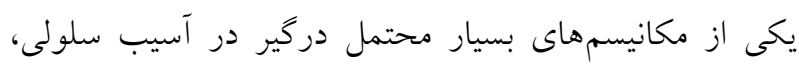

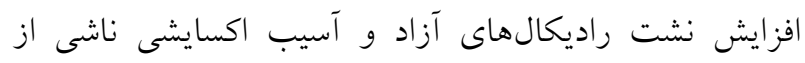

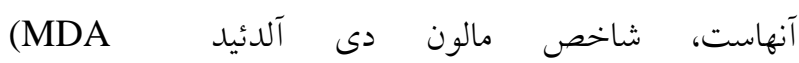
كه بيانخر مقدار يراكسيداسيون ليييد (Molondialdehyde)) اكسايشى (آسيب (1) (- n) 
مطالعات آزمايشگاهى نشان داده شده كه بذر كتان نه تنها به

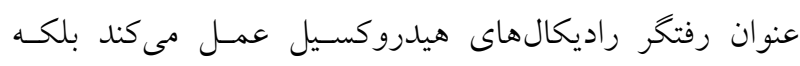

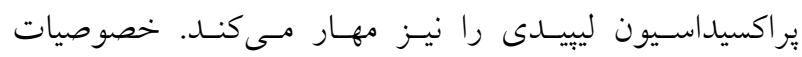

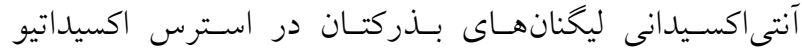

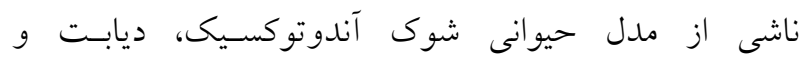
يولمونارى ايسكميك رى يرفيوزن و بيمارىهاى قلبى عروقى مانى

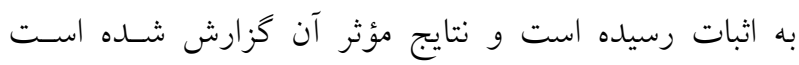

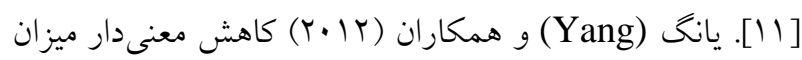

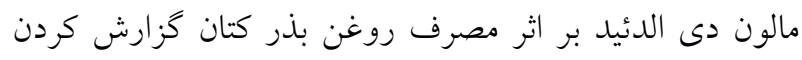

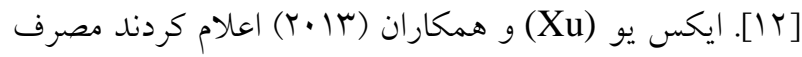

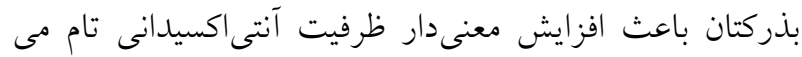

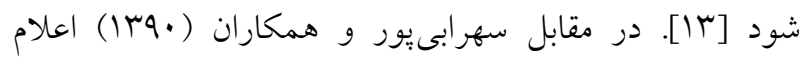

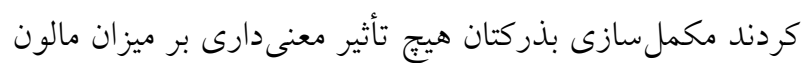

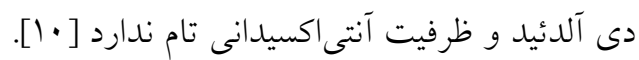

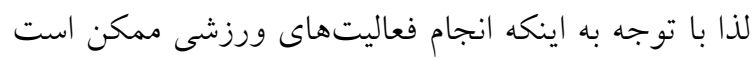

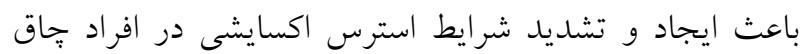
شود و از طرفى نظر به مطالعات محدود و متناقض در زمينه

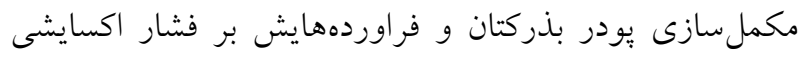
بويزه بعد از انجام فعاليت ورزشى مطالعه حاضر قصد دارد

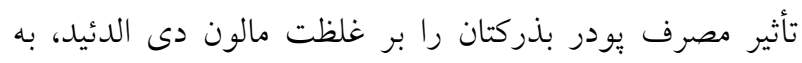

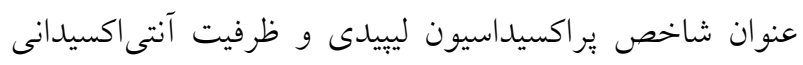

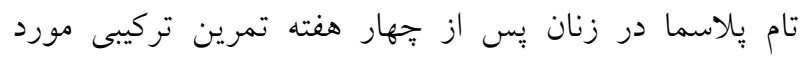

\section{مواد و روش ها - ماد}

تحقيق حاضر در قالب يك مطالعه تجربى جهار گروهى

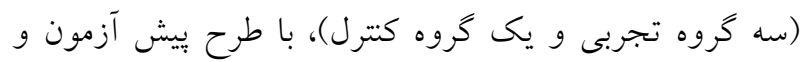

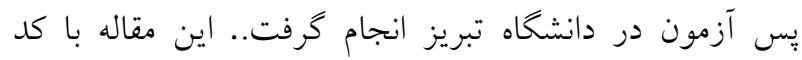

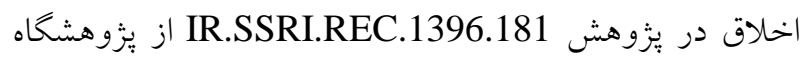

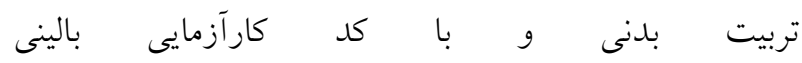
IRCT20171130037689N1

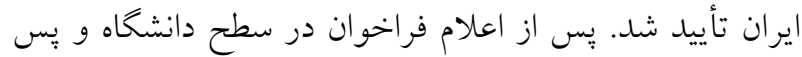

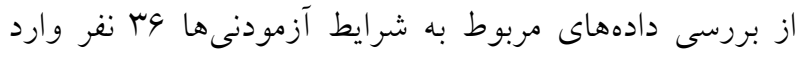

غلظت مالون دى آلدئيد يلاسما به عنوان شاخص استرس

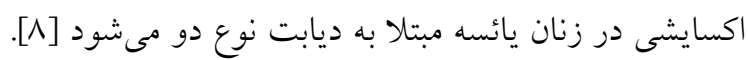

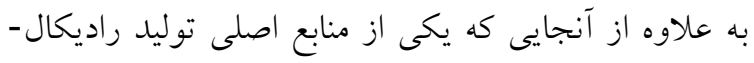

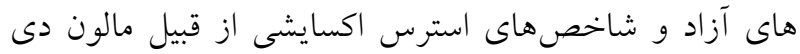

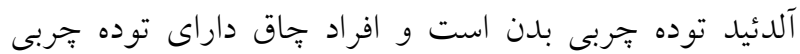
بيشترى نسبت به افراد با وزن طبيعى مىباشند، لذا اين احتمال وجود دارد كه در طى فعاليتهاى ورزشى ميزان توليد كونه-

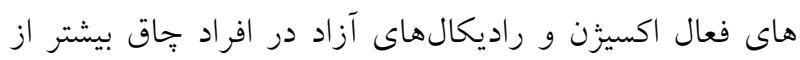

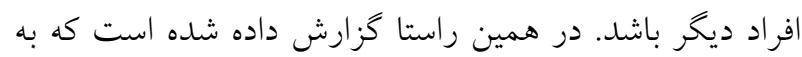

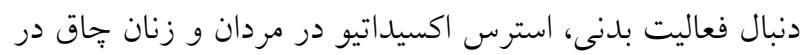

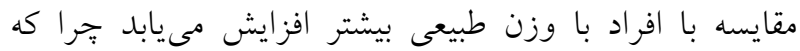

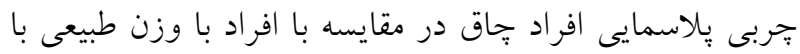

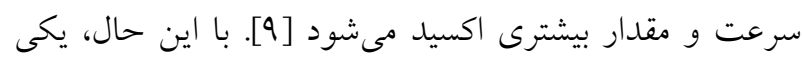

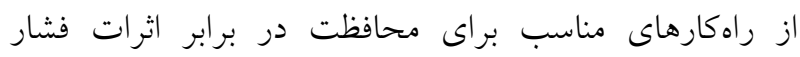

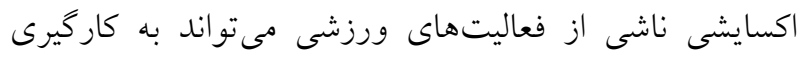
عوامل تغذيهاى و استفاده از مكملهاى آنتى اكسيدانى باشد. بـانه طورى كه، در سالهاى اخير توجه فزايندهاى مبنى بر اثربخشى مصرف مكمل هاى بويزه مكمل هاى گياهى و طبيعى در مقابله

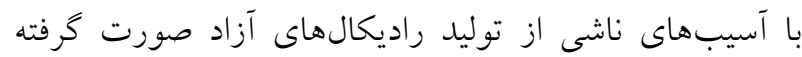

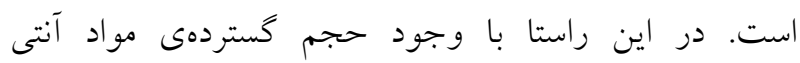

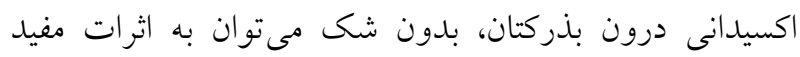

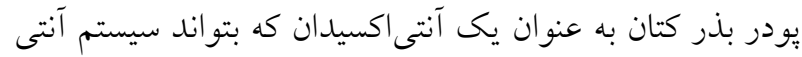

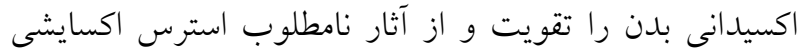
جلو گيرى كند، اشاره كرد [•l].

\section{Linum ـ Flax} usitatisimum مختلفى از جهان كشت مى شود. بذر كتان (Flaxseed; Fs)

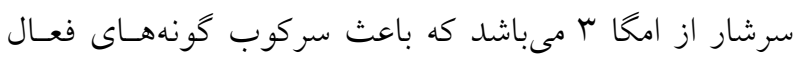

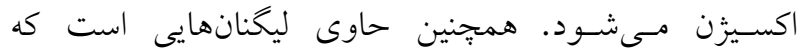

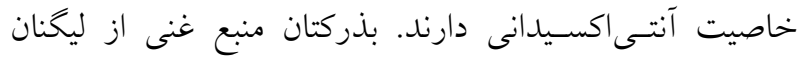
و هاى SDG (secoisolariciresinol diglucoside) مقـــادير كمترى از ليخنــــان ماتريسينول (Matairesinol) مى مانى

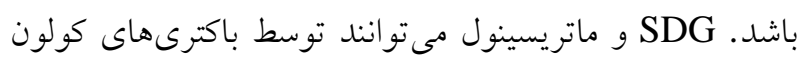

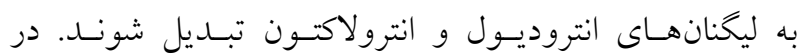


يرسشنامه ثبت فعاليت روزانه اندازهيرى شد. درصد جربى

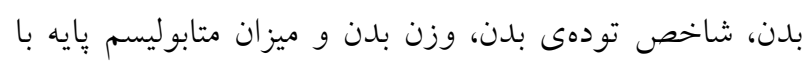

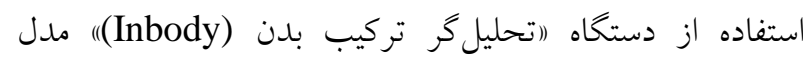

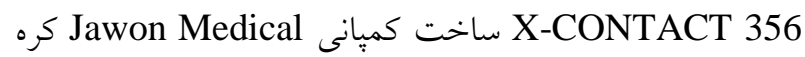

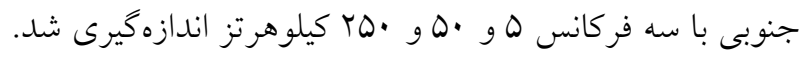

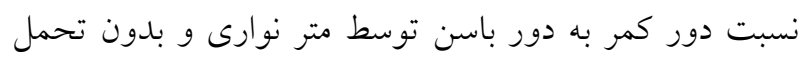

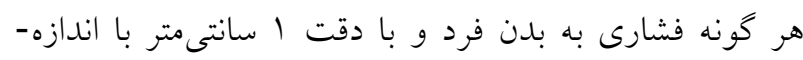

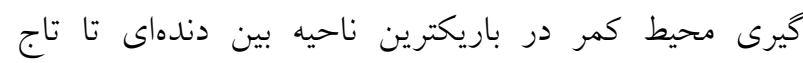

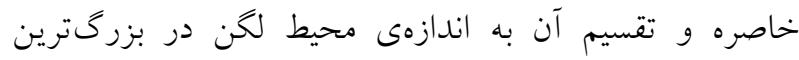

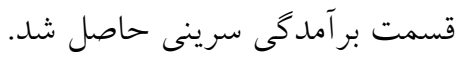

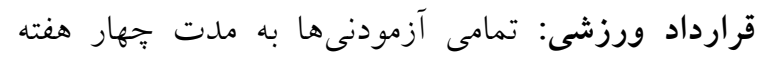
(جهار جلسهى دو ساعته در هفته) از روز هشتم دورهى ماهانه

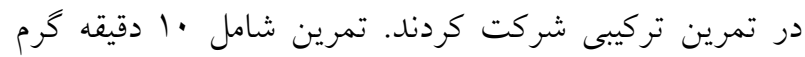

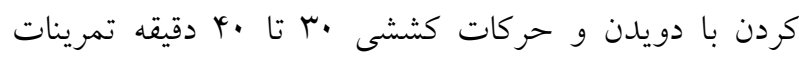

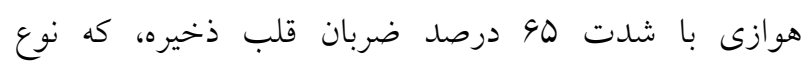

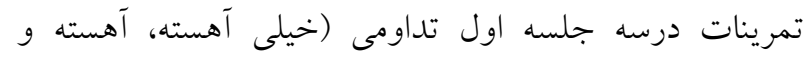

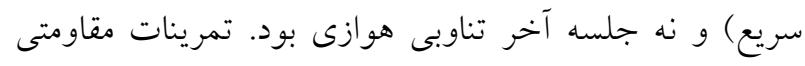

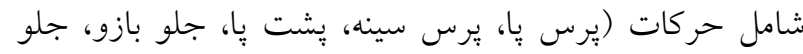

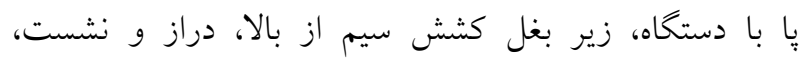

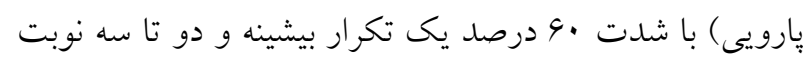

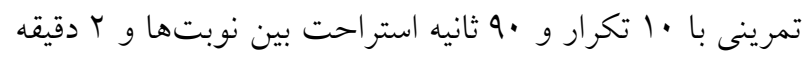

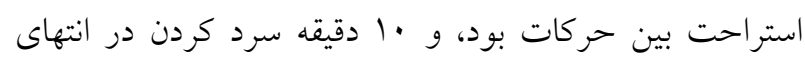

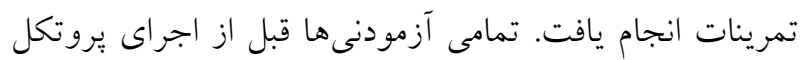

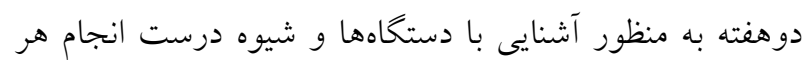

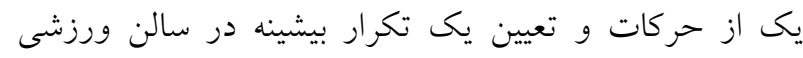

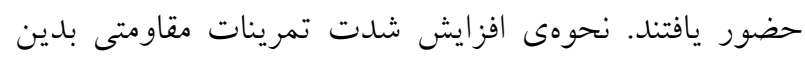

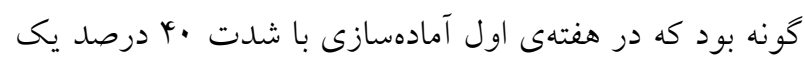

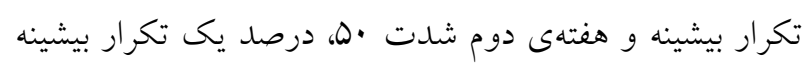

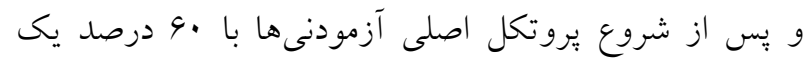

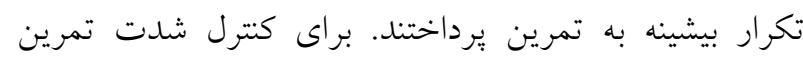

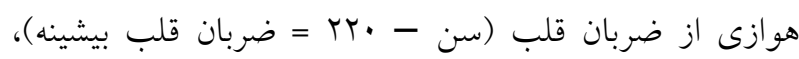

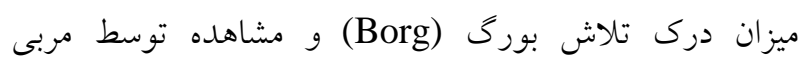

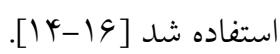

طرح تحقيق شدند. حجم نمونه با استفاده از نرمافزارهاى MedCal

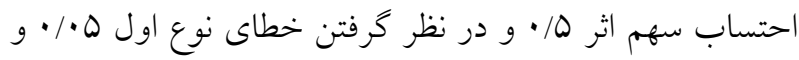

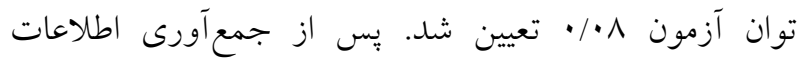

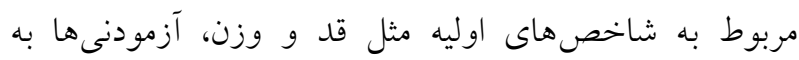

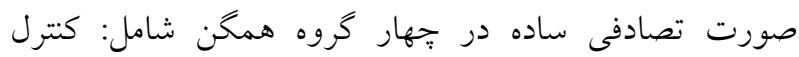

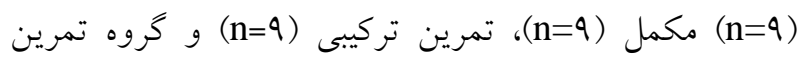

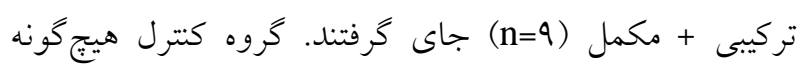

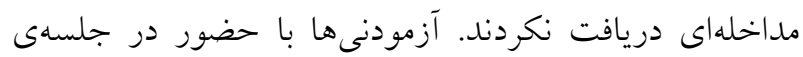

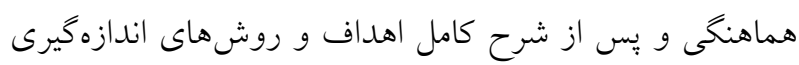

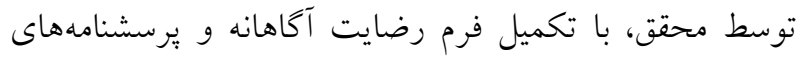

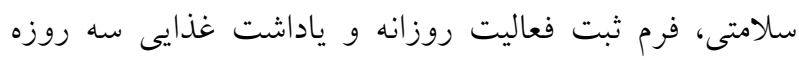

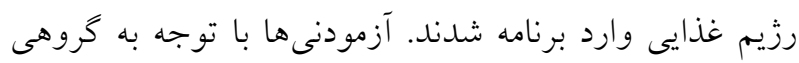

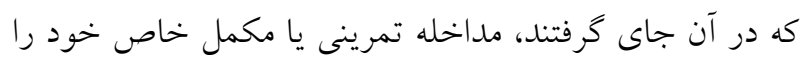

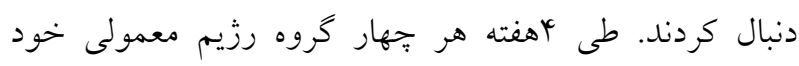

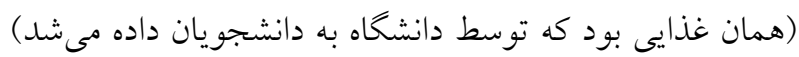

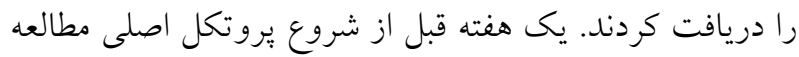

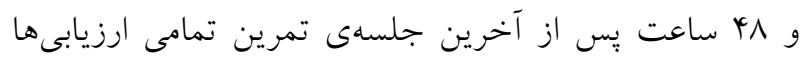

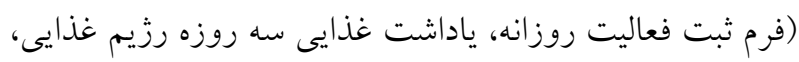

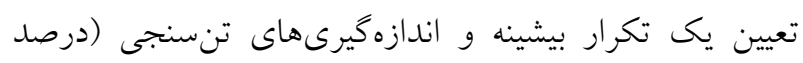

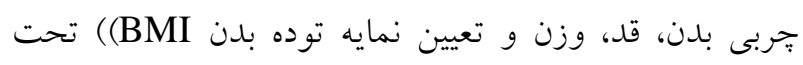

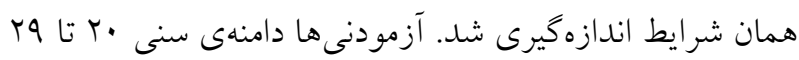

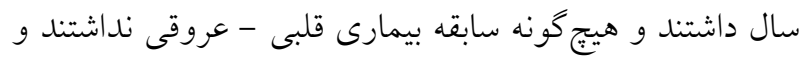

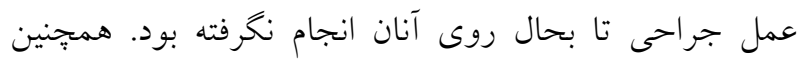

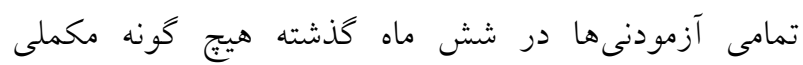

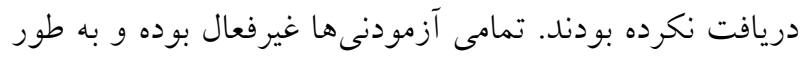

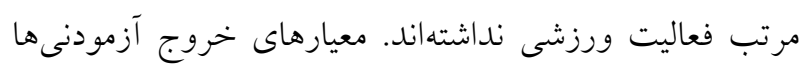
از مطالعه شامل عدم مصرف مكمل بذركتان، قطع بروتكل

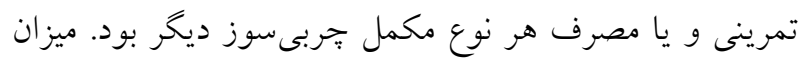

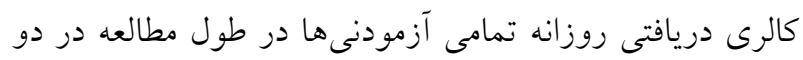

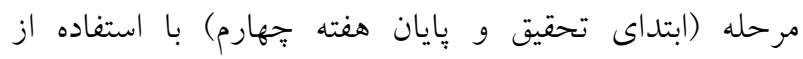

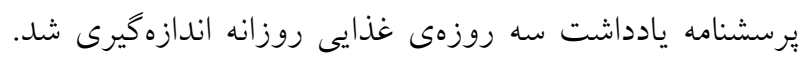

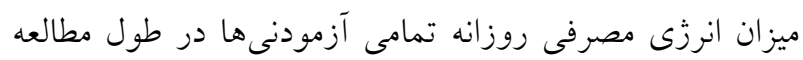

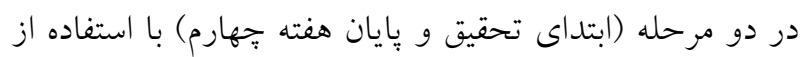




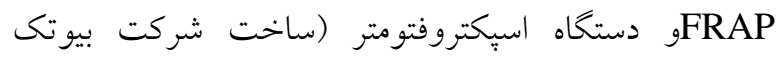
آمريكا) در طول موج سوه نانومتر مورد اندازهكيرى قرار كرفت. روشهاى تجزيه و تحليل آمارى: از آمار توصيفى براى

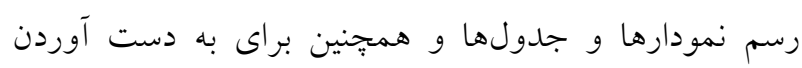

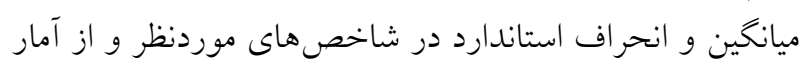

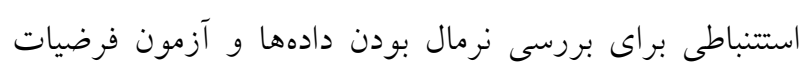
استفاده شد. براى بررسى طبيعى بودن دادهها از آزمون شاييرو - بردمال

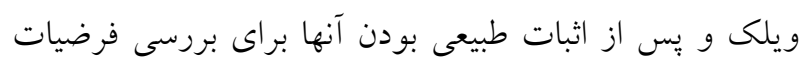

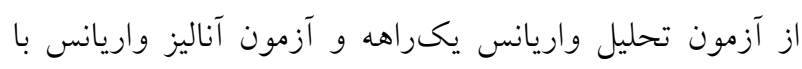

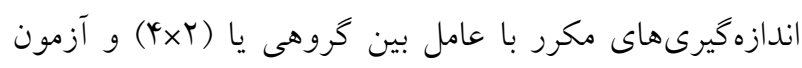

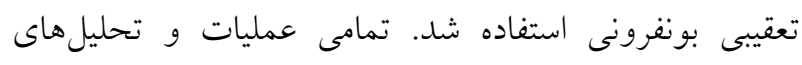

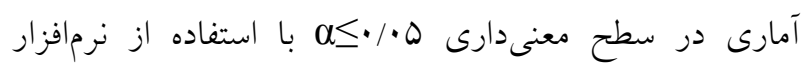
SPSS

نتايج در جدول شماره ا ميانخين و انحراف استاندارد مشخصات

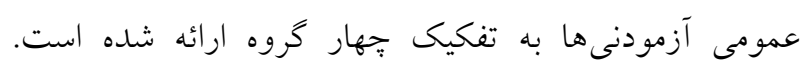
اطلاعات اين جدول بيانكر اين است كه تفاوت معنى دارى درد

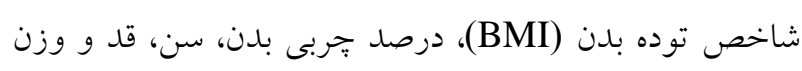

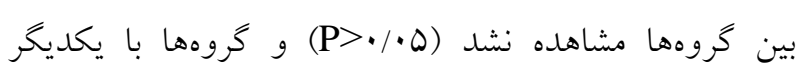

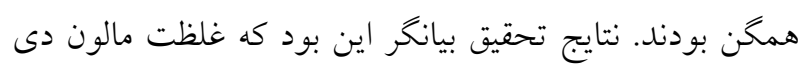
الديئد سرمى (MDA) در هر سه گروه داراى الكوى تغييرات

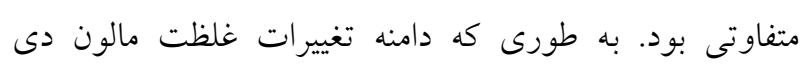

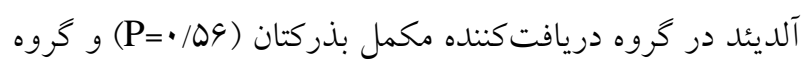
تمرين تركيبى با بذركتان (

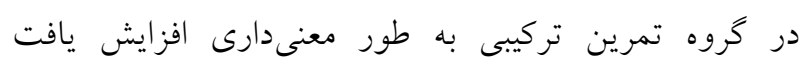

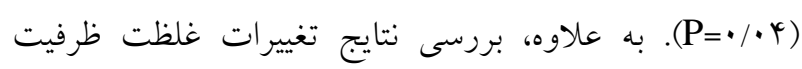

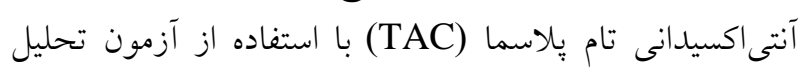

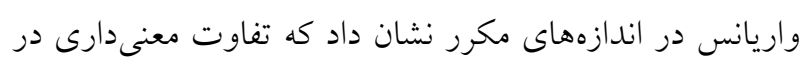

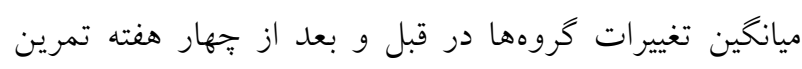

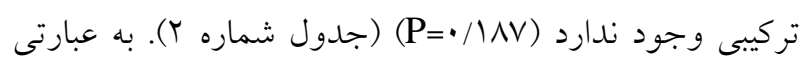
مصرف مكمل بذركتان و تمرين تركيبى بر دامنه تغييرات سرمى TAC تأثير معنى دارى ندارد.
مكملسازى: بذركتان مورد استفاده در اين مطالعه از شركت شفا يزوهان سبز در شهر تبريز تهيه شده كه در همانجا

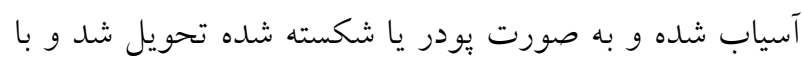

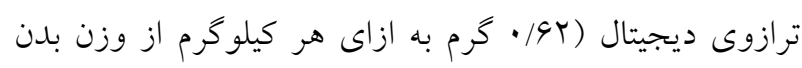

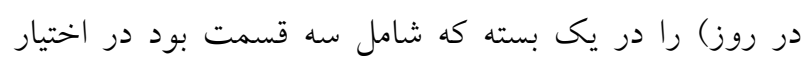

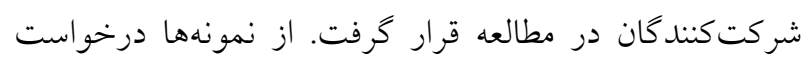

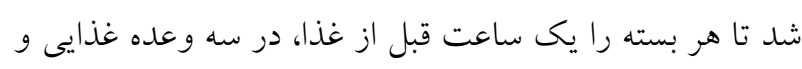

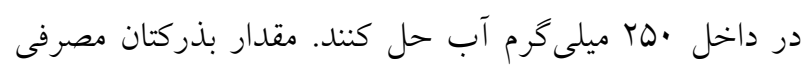

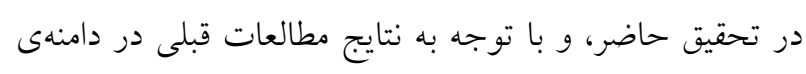

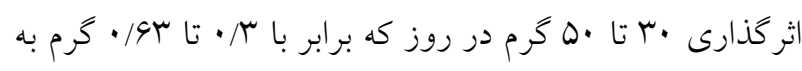

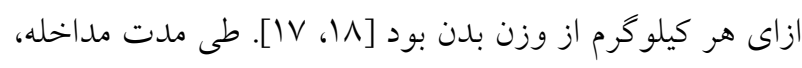

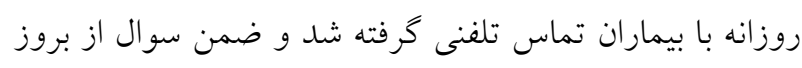

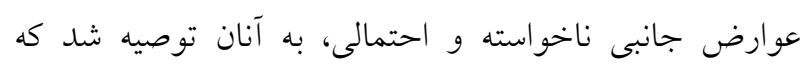
بستها را به طور مرتب مصرف كنند.

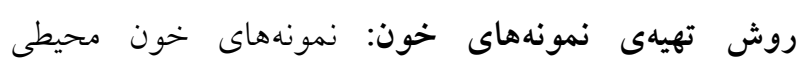

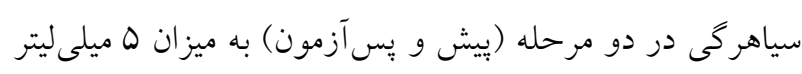

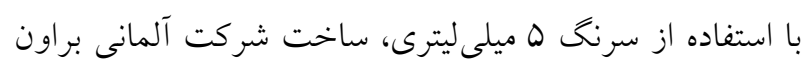

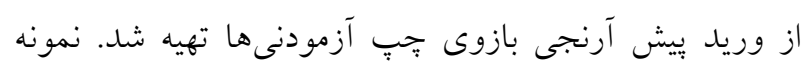

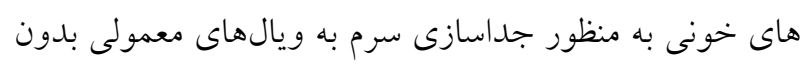
مادهى ضد انعقاد ريخته شد و با دستخاه سانتر يفيوز سرم تهيه شده و به ميكروتيوب انتقال يافتند. همهى نمونه إنها تا زمان

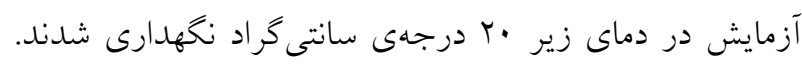

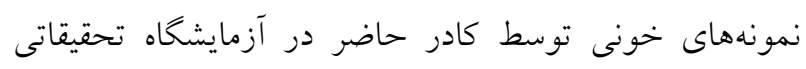

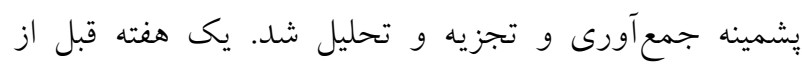

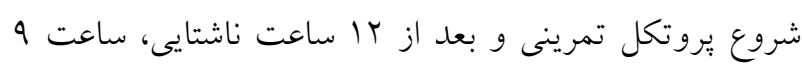

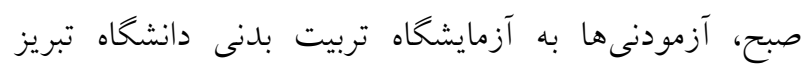

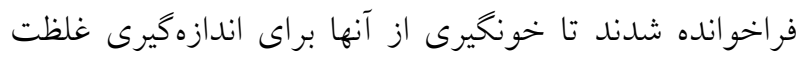

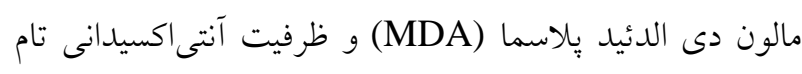

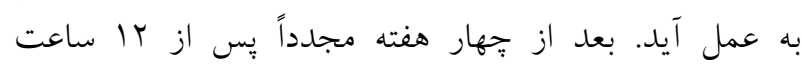

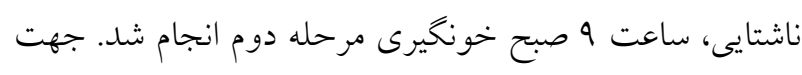

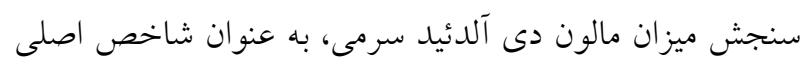

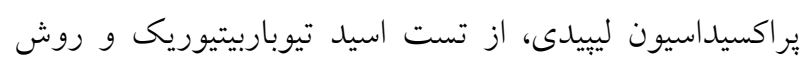

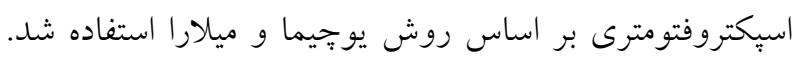

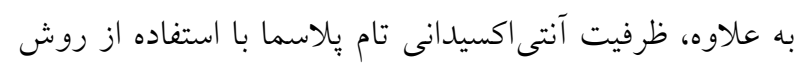


جدول شماره ا - ويزگى هاى دمو گر افيك آزمودنى ها قبل و بعد از مداخلات

\begin{tabular}{|c|c|c|c|c|c|}
\hline \multicolumn{4}{|c|}{ ميانخين土 انحراف استاندارد } & \multirow{2}{*}{\multicolumn{2}{|c|}{ شاخصها/كروهها }} \\
\hline تركيبى + مكمل (n=9) & تمرين تركيبى (n=9) & مكمل (n=9) & كنترل (q=n) & & \\
\hline$T Y / \pm \Delta \wedge Y / T Y$ & $r \Delta / 991 \pm / \Delta$. & $r Y / Y \cdot I \pm / \Delta r$ & $T Y / \pm Y \cdot T / Q Y$ & & سن (سال) \\
\hline $19 T / 0 r \pm 1 / 9 r$ & 19T/M \pm II... & $190 / 11 \pm r / 9 r$ & $190 / \cdot 4 \pm 1 / 9$. & & قد (سانتىمتر ) \\
\hline $99 / 9 \mu \pm r / \cdot 1$ & $99 / r \wedge \pm r / 9 r$ & $V Y / Q Y \pm Q / Q Y$ & $V Y / G Y \pm Y / \cdot r$ & قبل & \multirow{2}{*}{ وزن (كيلو گرم) } \\
\hline$G \Lambda / \Lambda \uparrow \pm Y / \Psi \wedge$ & $q \Lambda / v \cdot \pm \mu / \cdot \cdot$ & $V / / 9 \cdot \pm 9 / \cdot \cdot$ & $V \Psi / Y Y \pm Y / r q$ & بعد & \\
\hline$\Gamma T / Q T \pm 1 / T V$ & $\mu q / 4 V \pm 1 / 4 q$ & $r Y / Q \Lambda \pm 1 / 9 r$ & $M Y / M \cdot \pm I / N 4$ & قبل & \multirow[b]{2}{*}{ درصد خربى } \\
\hline$\mu r / 91 \pm 1 / 94$ & $r r / q 1 \pm 1 / v q$ & $M 1 / 00 \pm 1 / 99$ & $r Y / \Lambda \Lambda \pm 1 / \mu_{G}$ & بعد & \\
\hline$r V / 19 \pm 1 / 1$. & $r q / 49 \pm 1 / 1 V$ & $r Q / 99 \pm \cdot / 94$ & $r V / \cdot r \pm \cdot / N \Delta$ & قبل & شاخص تودمى بدنى \\
\hline$r V / \cdot r \pm 1 / \cdot 0$ & $r 9 / 19 \pm 1 / r$. & $r \Delta / \cdot \Delta \pm \cdot / 4 \mid$ & $r V / \cdot r \pm 1 / \cdot 1$ & بعد & (كيلو كرم/مجذور متر) \\
\hline
\end{tabular}

جدول شماره Y- نتايج آمارى متغيرهاى مورد مطالعه در قبل و بعد از جهار هفته

\begin{tabular}{|c|c|c|c|c|c|c|}
\hline \multirow{2}{*}{ p- value } & \multirow{2}{*}{ p- value } & \multirow{2}{*}{ p-value $\dagger$} & \multicolumn{2}{|c|}{ ميانخين انحر اف معيار } & \multirow{2}{*}{ كروهها } & \multirow{2}{*}{ 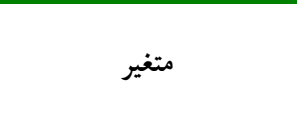 } \\
\hline & & & بعد & قبل & & \\
\hline \multirow{4}{*}{$* \cdot / \cdot \cdot 1$} & \multirow{4}{*}{$\cdot / T Y}$. &.$/ 11 \mathrm{~V}$ & $r / 99 \pm \cdot / 19$ & $r / 9 \Lambda \pm 1 / 1 r$ & كنترل & \multirow{4}{*}{ MDA (نانومول/ميلىليتر) } \\
\hline & & $\cdot / 094$ & $\mu / r^{\mu} \pm \cdot / \wedge \Delta$ & $r / \cdot v \pm 1 / / r$ & مكمل & \\
\hline & & $* / \cdot 4$ & $r / \Delta Q \pm \cdot / 9 r$ & $r / V \Lambda \pm 1 / 11$ & تمرين تركيبى & \\
\hline & & $\cdot / \mathrm{NI}$ & $r / 9 T \pm \cdot / V V$ & $r / 11 \pm 1 / 19$ & تر كيبى + مكمل & \\
\hline \multirow{4}{*}{$\cdot / \wedge \wedge \vee$} & \multirow{4}{*}{.$/ 011$} & $\cdot / 1 \cdot 1$ & $1 / r r \pm \cdot / 1 r$ & $1 / Y \mu \pm \cdot / K$ & كنترل & \multirow{4}{*}{ TAC (ميلى مول/ ليتر ) } \\
\hline & & $\cdot$ /VTq & $1 / T Y \pm \cdot / 1$ & $1 / Y \wedge \pm \cdot / 1$ & مكمل & \\
\hline & & $\cdot / \mathrm{VIV}$ & $1 / T \cdot \pm \cdot / \cdot 1$ & $1 / \Gamma 1 \pm \cdot / 19$ & تمرين تركيبى & \\
\hline & & $\cdot / M Y$ & $1 / T \Delta \pm \cdot / 1 T$ & $1 / T V \pm \cdot / / V$ & تر كيبى + مكمل & \\
\hline
\end{tabular}

اسكلتى افزايش مىيابد و در نتيجه علىرغم فوايد سلامتى

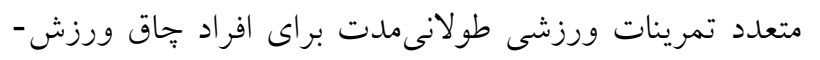

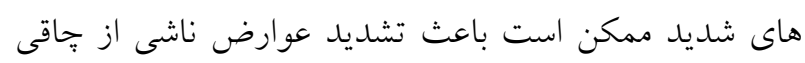
از قبيل ديابت و نفروياتى شود. لذا شناخت و ارائه راهكار

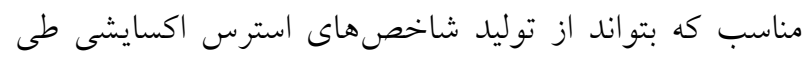

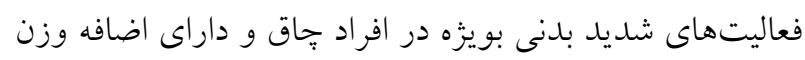

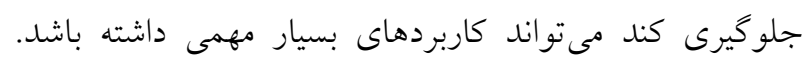

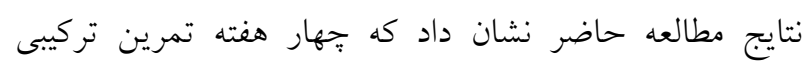
باعث افزايش معنىدار غلظت مالون دى الدئيد پيلاسما
اگرجهه اغلب مطالعات نشان دادهاند كه تمرينات ورزشى منظم و طولانىمدت اثرات سودمندى بر سلامت افراد جامعه بويزه افراد جاق دارد، اما شواهد مستقيم و غيرمستقيم بيانكر

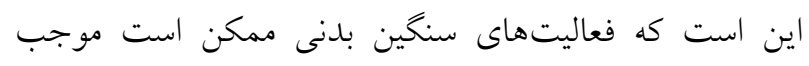

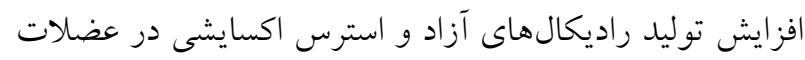

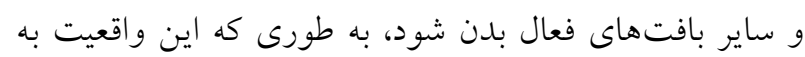

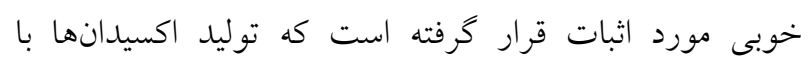
افزايش ميزان فعاليتهاى متابوليك ناشى از انقباضات عضلات 
برنامههاى ورزشى منظم، سازگًارىهاى آنتى اكسيدانى مناسبى

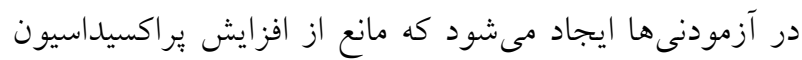

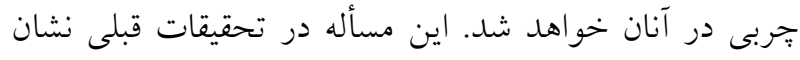

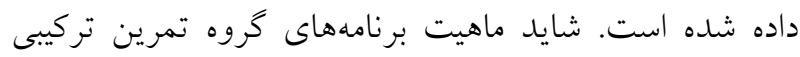

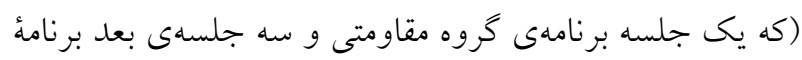

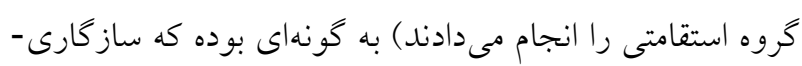

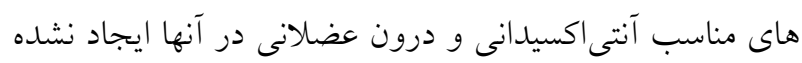

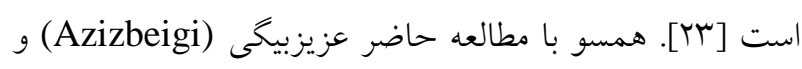

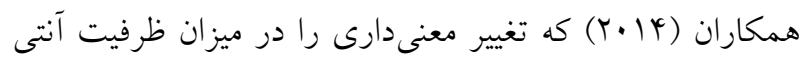

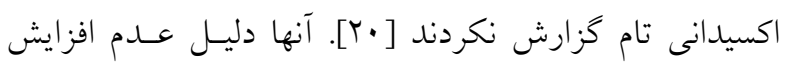

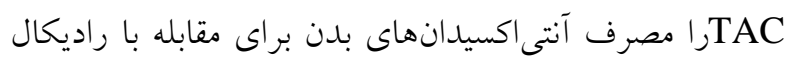

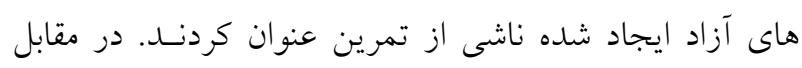

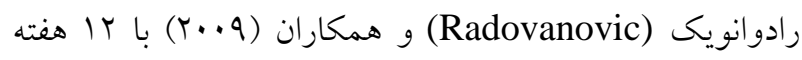

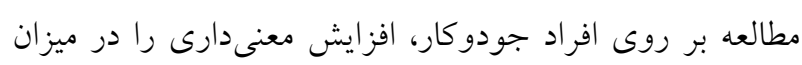

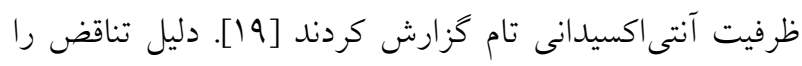

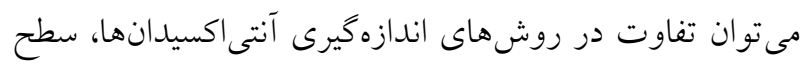

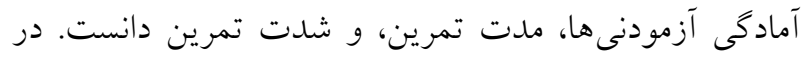

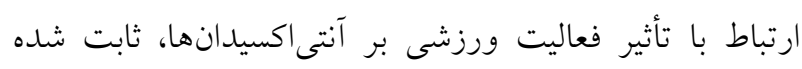

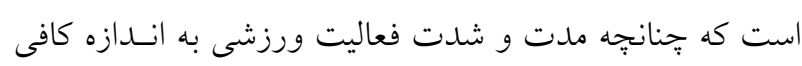
باشد، ظرفيت آنتى اكسيدانى تغيير خواهد كرد.

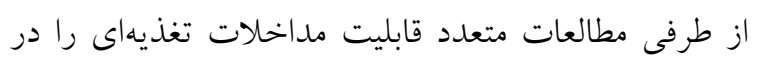

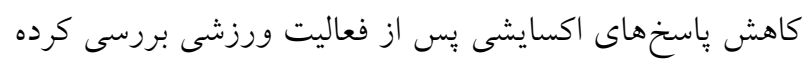

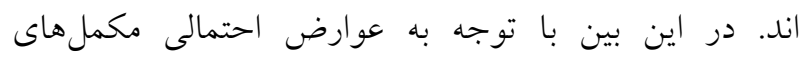

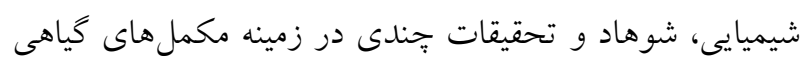

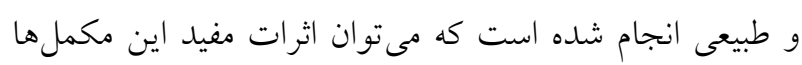

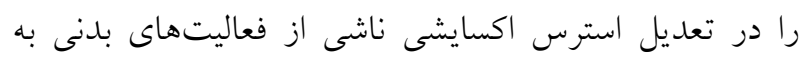

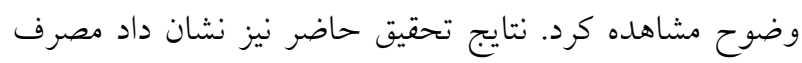

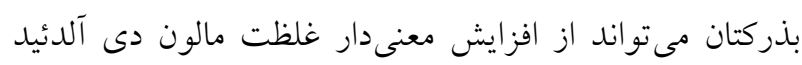

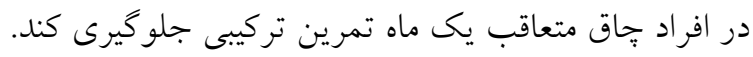

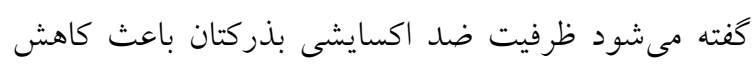

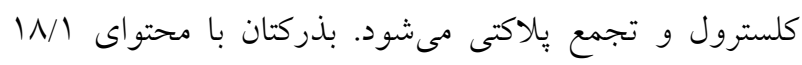

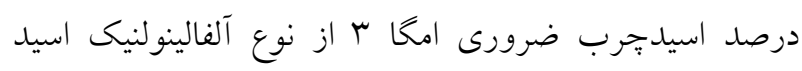

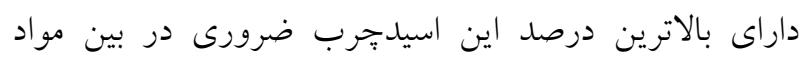

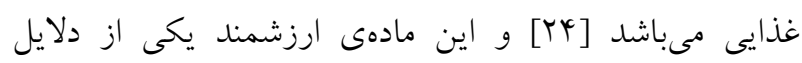

(MDA)، به عنوان شاخص يراكسيداسيون لييدى، در گروه

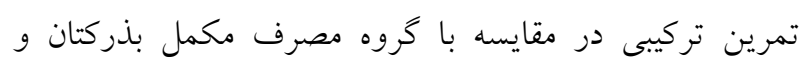

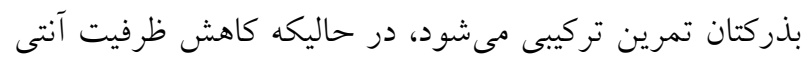

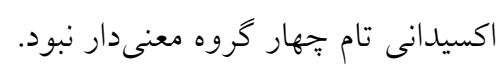

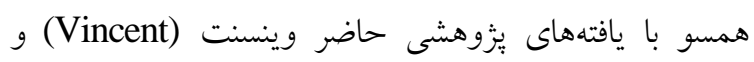

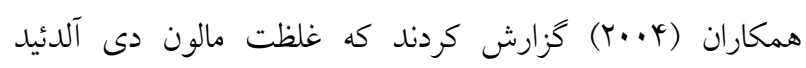

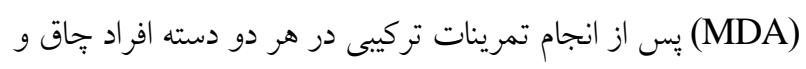

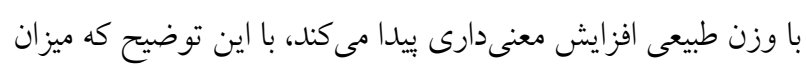

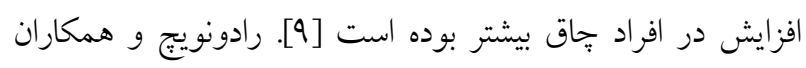

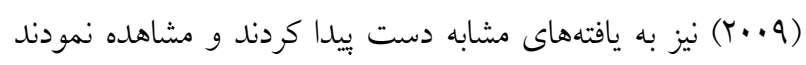

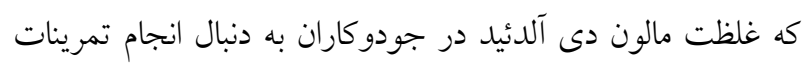
تركيبى مقاومتى - استقامتى افزايش مى يابد [19].

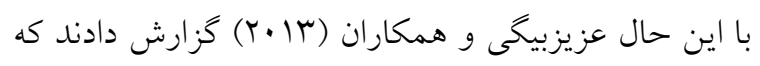

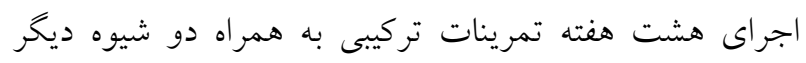

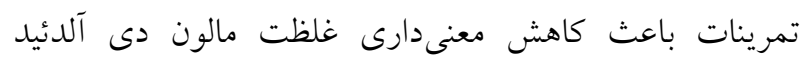

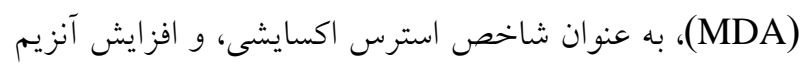

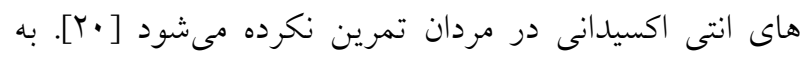

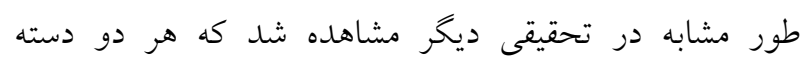

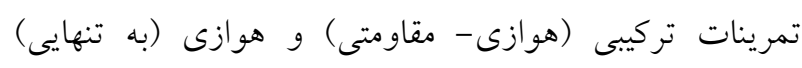

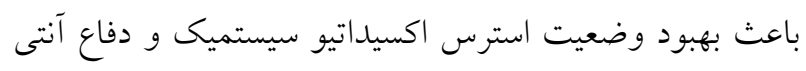

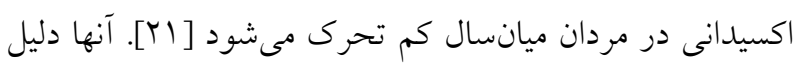

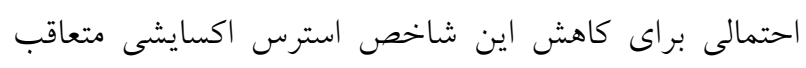

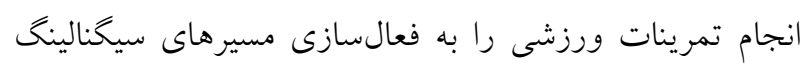

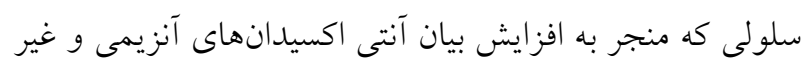

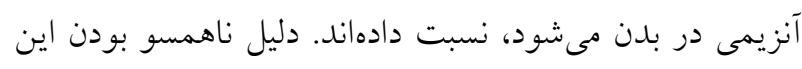

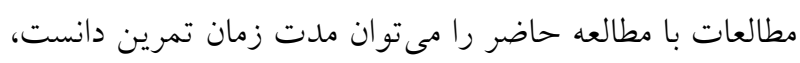

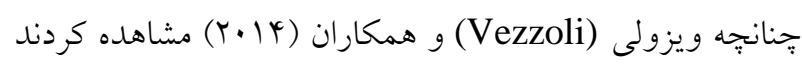

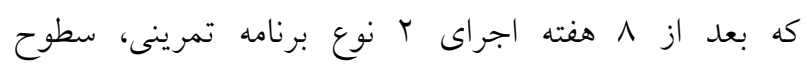

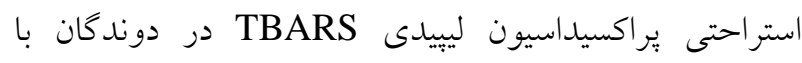

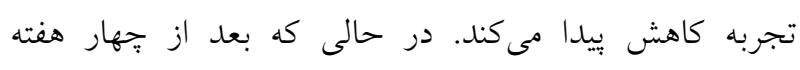

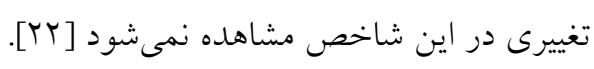

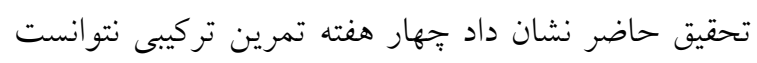
افزايش معنى دارى در ميزان ظرفيت آنتىاكسيدانى تام ايجاد

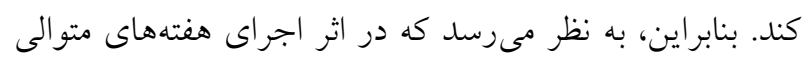


تأثير مكمل سازى بذر كتان ...

و همجنين تخريب كاروتنوئيدها روغن تخم كتان بود. اثرات

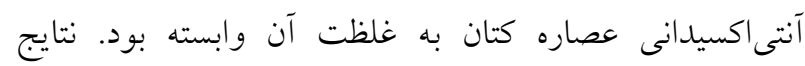
تحقيات نشان مىدهد كه تركيبات فنولى (SDG) و وِروتئينى

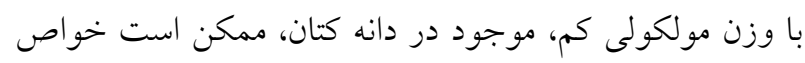

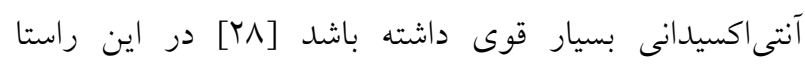

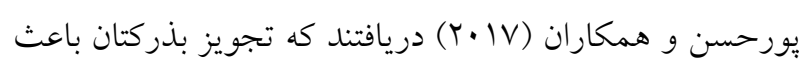

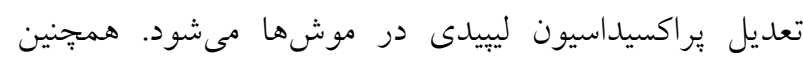

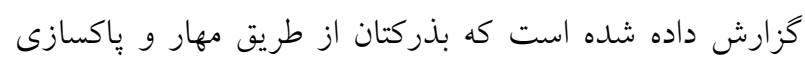

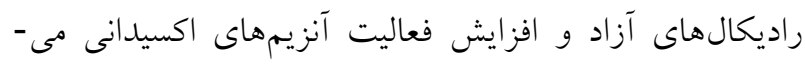

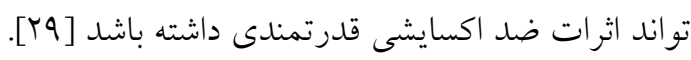

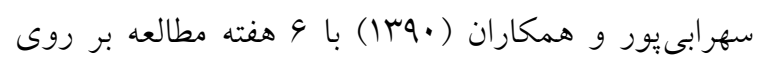
هr سر موش صحرايى نابالغ اعلام كردند مكملسازى بذركتان

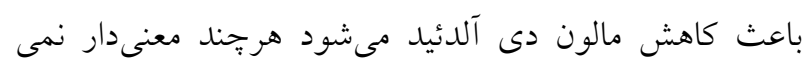

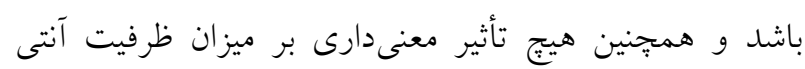

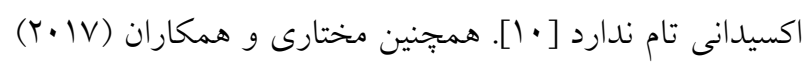

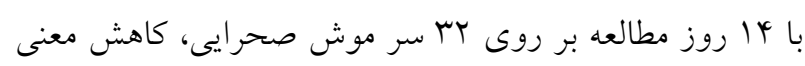

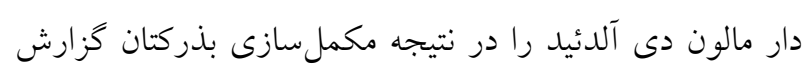

كردند [r.

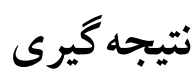

لذا مطالعه حاضر و مطالعات مشابه مذكور مىتواند حاوى

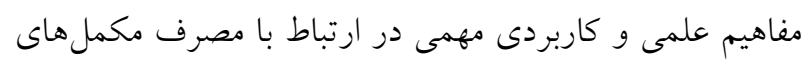

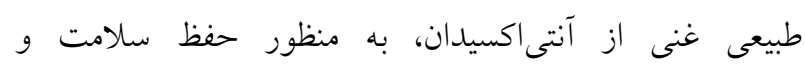
جلو گيرى از آسيبهاى استرس اكسايشى ناشى از فعاليتهاى أنسي

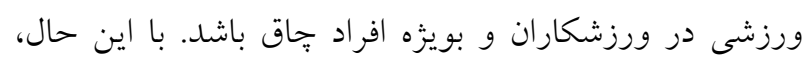

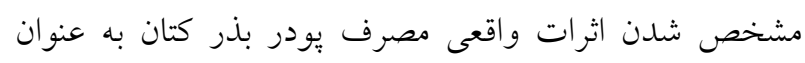

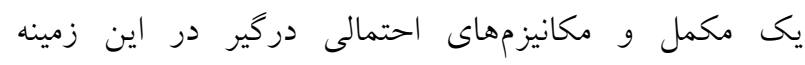
تحقيقات بيشتر و جامع ترى را مى طلبد.
بالارفتن ظرفيت ضداكسايشى شمرده مىشود. در داخل بدن

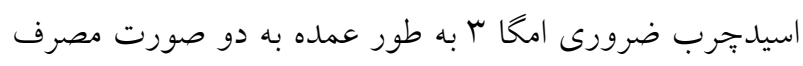

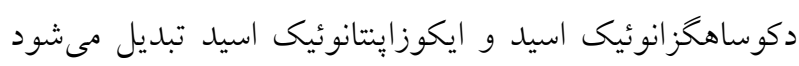

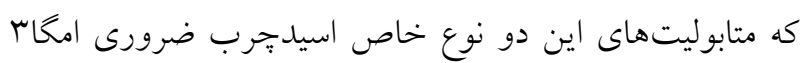

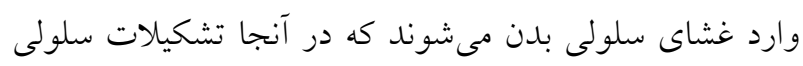

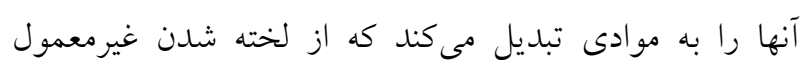

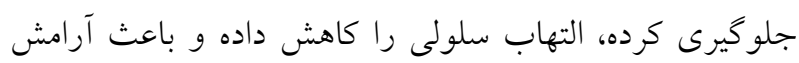

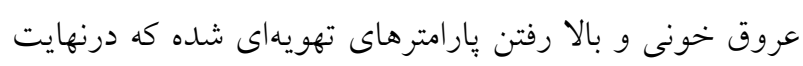

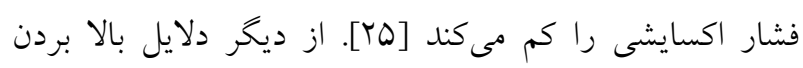

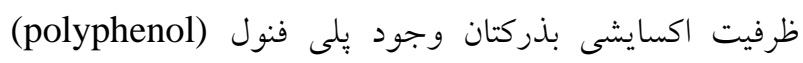

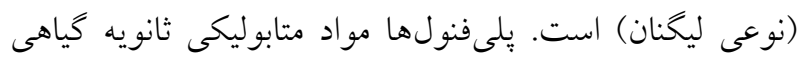

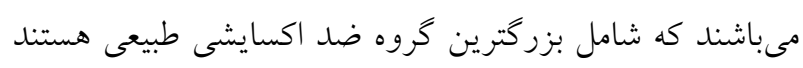

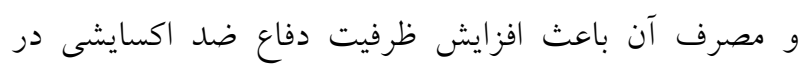

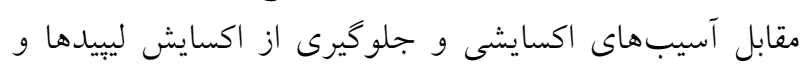

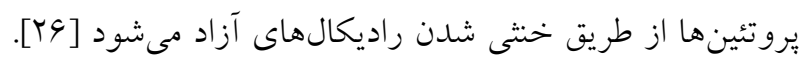

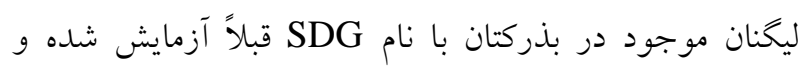

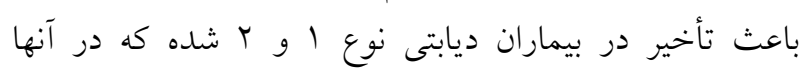
ظرفيت ضد اكسايشى را از طريق سركوب بيان زئ زن آنس آنزيم

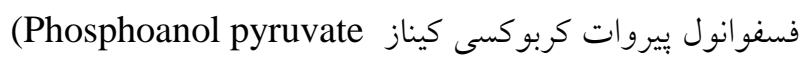
carboxy kinase) عصاره خالص محلول در آب به دست آمده از دانه كتان

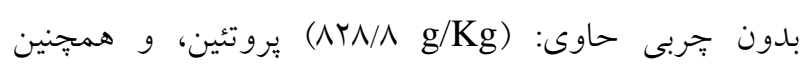

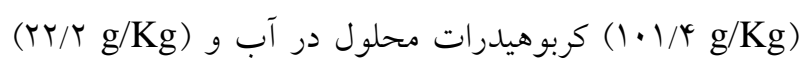

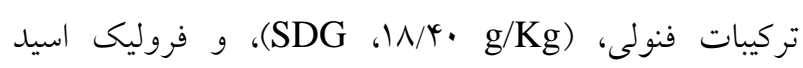

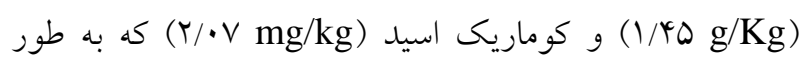

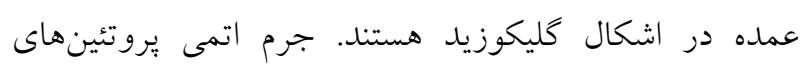

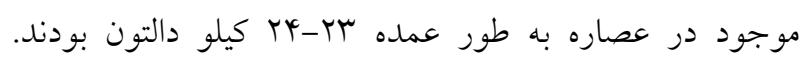
عصاره كتان در يكى مدل سيستم امولسيون، قادر به مهار توليد محصولات اكسيداسيون (ديانكونزو گه، يراكسيدها و آلدئيدها) 
1. Kazemi M, Marandi S M, Movahedian Attar A, Haghighatian $M$ and Rezaei Z. Effect of acute exercise on total antioxidant capacity and hydrogen peroxide in male Wistar rats: J. Practical Studies At Biosciences In Sport 2014; 2 (3): 29- 37.

2. Ga'ini A A, Sheikholeslami Vatan D, Ashrafi Helen J and Mogharnasi M. Short-term and longterm effects of three types of fasting, endurance and combination of sport activity on the amount of lactate hydrogenase, creatine kinase and plasma malondialdehyde in rats. Sports Journal of Sport Sciences 2011; 3 (8): 5-20.

3. Forsythe L K, Wallace J M and Livingstone M B

E. Obesity and inflammation: the effects of weight loss. Nutrition Research Rev. 2008; 21 (2): 117-133.

4. Parisi S M and Goodman E. Obesity and cardiovascular disease risk in children and adolescents. Current Cardiovascular Risk Reports 2008; 2 (1): 47-52.

5. Atashak S, Niloufari A and Azizbighi K. The effect of short-term supplemental Blackberry extract on total antioxidant capacity of the plasma and lipid oxidation index of obese men following one session of resistance activity. Food Science and Nutrition 2014; 11 (spring 1393): 55-62.

6. Thirumalai $T$, Therasa $S \mathrm{~V}$, Elumalai $\mathrm{E}$ and David E. Intense and exhaustive exercise induce oxidative stress in skeletal muscle. Asian Pacific $J$. Tropical Disease 2011; 1 (1): 63-66.

7. Jahani G, Firoozrai M, Matin Homaee H, Tarverdizadeh B, Azarbayjani M A, Movaseghi G R, Sarasghani M R and Hedayatzadeh R. The Effect of Continuous and Regular Exercise on Erytrocyte Antioxidative Enzymes Activity and Stress Oxidative in Young Soccer Players. Razi J. Medical Sciences 2010; 17 (74): 22-32.

8. Azamian Jazi A and Shokouhi R. The Effect of an Eight Week Combined Exercise Training on Oxidative Stress and Lipid Peroxidation in Postmenopausal Women with Type 2 Diabetes.
The Journal of Shahid Sadoughi University of Medical Sciences 2016; 24 (8): 667-678.

9. Vincent H K, Morgan J W and Vincent K R. Obesity exacerbates oxidative stress levels after acute exercise. Medicine and Science in Sports and Exercise 2004; 36 (5): 772-779.

10. Shahla S P, Adela J, Mohammad K, Abdolfattah S, Tahereh C o S and hamidreza S. The effect of oxidative stress in immature rat rats with varicocele. Physiology and Pharmacol. 1390; 3 (15):416-426.

11. Adolphe J L, Whiting S J, Juurlink B H, Thorpe L $\mathrm{U}$ and Alcorn J. Health effects with consumption of the flax lignan secoisolariciresinol diglucoside. British Journal of Nutrition 2010; 103 (7): 929-938.

12. Yang W, Fu J, Yu M, Huang Q, Wang D, Xu J, Deng Q, Yao P, Huang F and Liu L. Effects of flaxseed oil on anti-oxidative system and membrane deformation of human peripheral blood erythrocytes in high glucose level. Lipids in Health and Disease 2012; 11 (1): 88.

13. Xu J, Gao H, Song L, Yang W, Chen C, Deng Q, Huang Q and Huang F. Flaxseed oil and alphalipoic acid combination ameliorates hepatic oxidative stress and lipid accumulation in comparison to lard. Lipids in Health and Disease 2013; 12 (1): 58.

14. DiCarlo L, Sparling P, Millard-Stafford $M$ and Rupp J. Peak heart rates during maximal running and swimming: implications for exercise prescription. International J. Sports Med. 1991; 12 (03): 309-312.

15. Soori R, Rezaeian N, Khosravi N, Ahmadizad $S$, Taleghani $H$, Jourkesh $M$ and Stannard S. Effects of water-based endurance training, resistance training, and combined water and resistance training programs on visfatin and ICAM-1 levels in sedentary obese women. Science \& Sports 2017; 32 (3): 144-151. 
تأثير مكمل سازى بذر كتان ... - ت

16. Agha Alinejad H, Mehrabani J, Ansari Dogahe R and Piri M. The Influence of Resistance, Endurance, and Combined Resistance-endurance Exercise Training on Interleukin-18 and C-reactive Protein Level in Inactive Female Adolescents. Tabari Journal of Preventive Medicine 2016; 2 (1): 38-47.

17. Ursoniu S, Sahebkar A, Andrica F, Serban C and Banach M. Effects of flaxseed supplements on blood pressure: A systematic review and metaanalysis of controlled clinical trial. Clinical Nutrition 2016; 35 (3): 615-625.

18. Ju Y. Can flaxseed lower cholesterol levels? Produced by Virginia Cooperative Extension. 2017, pp: 1-7.

19. Radovanovic D, Bratic $M$, Nurkic $M$, Cvetkovic T, Ignjatovic A and Aleksandrovic M. Oxidative stress biomarker response to concurrent strength and endurance training. Gen. Physiol. Biophys. 2009; 28 (Special Issue): 205-211.

20. Azizbeigi K, Stannard S R, Atashak $S$ and Haghighi MM. Antioxidant enzymes and oxidative stress adaptation to exercise training: comparison of endurance, resistance, and concurrent training in untrained males. Journal of Exercise Science \& Fitness 2014; 12 (1): 1-6.

21. Schaun M I, Dipp T, Silva Rossato J, Wilhelm E N, Pinto R, Rech A, Plentz R D M, Homem de Bittencourt P I and Reischak-Oliveira A. The effects of periodized concurrent and aerobic training on oxidative stress parameters, endothelial function and immune response in sedentary male individuals of middle age. Cell Biochemistry and Function 2011; 29 (7): 534-542.

22. Vezzoli A, Pugliese L, Marzorati M, Serpiello F R, La Torre A and Porcelli S. Time-course changes of oxidative stress response to highintensity discontinuous training versus moderateintensity continuous training in masters runners. PLoS One 2014; 9 (1): e87506.

23. Abbasali G, Dariush S V, Jawad A H and Mahdi M. Short-term and long-term effects of three types of exercise activity, endurance and combination on the amount of lactate hydrogenase, creatine kinase and malondialdehyde in rats. Sports Sciences (Motion) 1390; 8: 5-20.

24. Jangale N M, Devarshi P P, Dubal A A, Ghule A E, Koppikar S J, Bodhankar S L, Chougale A D, Kulkarni M J and Harsulkar A M. Dietary flaxseed oil and fish oil modulates expression of antioxidant and inflammatory genes with alleviation of protein glycation status and inflammation in liver of streptozotocin-nicotinamide induced diabetic rats. Food Chem. 2013; 141 (1): 187-195.

25. Asif M. Health effects of omega-3, 6, 9 fatty acids: Perilla frutescens is a good example of plant oils. Oriental Pharmacy \& Experimental Medicine 2011; 11 (1): 51-59.

26. Pilar B C, da Costa Güllich A A, Ströher D J, Zuravski L, Mezzomo J, Coelho R P, Faoro D, Piccoli J d C E and Manfredini V. 28-days dietary supplementation with golden flaxseed improves biochemical and oxidative parameters in patients with metabolic syndrome. Journal of Functional Foods 2014; 10: 232-242.

27. Katare C, Saxena S, Agrawal S, Prasad G and Bisen P. Flax seed: a potential medicinal food. $J$. Nutr. Food Sci. 2012; 2 (120): 2.

28. Waszkowiak $\mathrm{K}$ and Barthet $\mathrm{V} J$. Characterization of a Partially Purified Extract from Flax (Linum usitatissimum L.) Seed. Journal of the American Oil Chemists' Society 2015; 92 (8): 1183.1194.

29. Poorhassan M, Mahakizadeh $S$, Bazrafkan $M$, Nikmehr B, Abolhassani F, Ijaz S, Yamini N, Dashti N, Akbari M and Hassanzadeh G. Flaxseed can reduce the damages induced by hypoxia in the testis of rat. Int. J. Fertil. Steril. 2017; 12 (3): 7-1.

30. Mokhtari T, Faghir Ghanesefat $H$, Hassanzadeh G, Moayeri A, Jafar Haeri S M, Rezaee Kanavee A and Mousavi S M. Effects of Flaxseed oil supplementation on renal dysfunction due to ischemia/reperfusion in rat. Journal of Basic Research in Medical Sciences 2017; 4 (1): 22-29.

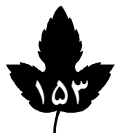

فصلنامه كياهان دارويى، سال هجدهم، دوره دوم،

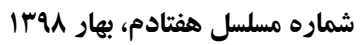




\title{
Effect of Flaxseed Supplementation and Concurrent Physical Activity on Total Antioxidant Capacity of the Plasma and the Lipid Peroxidation Index of Overweight Women
}

\author{
Halalkhor F (M.Sc.) \\ Faculty of Physical Education and Sport Sciences, University of Tabriz, Tabriz, Iran \\ *Corresponding author: East Azarbaijan, Tabriz, 29 Bahman BLVD, University of Tabriz, \\ Faculty of Physical Education and Sport Sciences \\ Tel: +98-936-8273304 \\ E-mail: fateme.halalkhor@gmail.com
}

\begin{abstract}
Background: Obesity is associated with increased oxidative stress. In addition, exercise can increase oxidative stress effects. However, the use of dietary supplements may moderate these indices.

Objective: The present study is conducted to assess the effect of flaxseed supplementation on the total antioxidant capacity and lipid peroxidation after four weeks concurrent training in overweight women.

Methods: Thirty six overweight women with BMI> 25 were randomly divided into four groups of 9 people, including supplementary training, concurrent training, supplementation flaxseed and control. All written consent was taken. Concurrent training included aerobic exercises with an intensity of $65 \%$ of heart rate and resistance training with intensity of $60 \% 1 \mathrm{RM}$ In between the Flaxseed powder $(0.62 \mathrm{~g}$ per $\mathrm{kg}$ of body weight per day) was supplemented during the four-week period. Hypothesis research at the level of significance $P<0.05$ was used to analyze the variance (ANOVA) with repeated measurements with inter-group factor.

Results: The results showed that the concentration of malondialdehyde biomarker in the nonflax seed group increased significantly after the concurrent training $(\mathbf{P}<\mathbf{0 . 0 5})$. However, the total antioxidant capacity of plasma was not significantly different $(P>0.05)$.

Conclusion: The results of this study indicated that acute concurrent Physical activity give rise to increased MDA concentration in overweight women. The application of flaxseed extract employed as an antioxidant supplement might ameliorate this marker and prevent the oxidative stress damage.
\end{abstract}

Keywords: Concurrent training, Flaxseed Supplementation, Oxidative Stress 